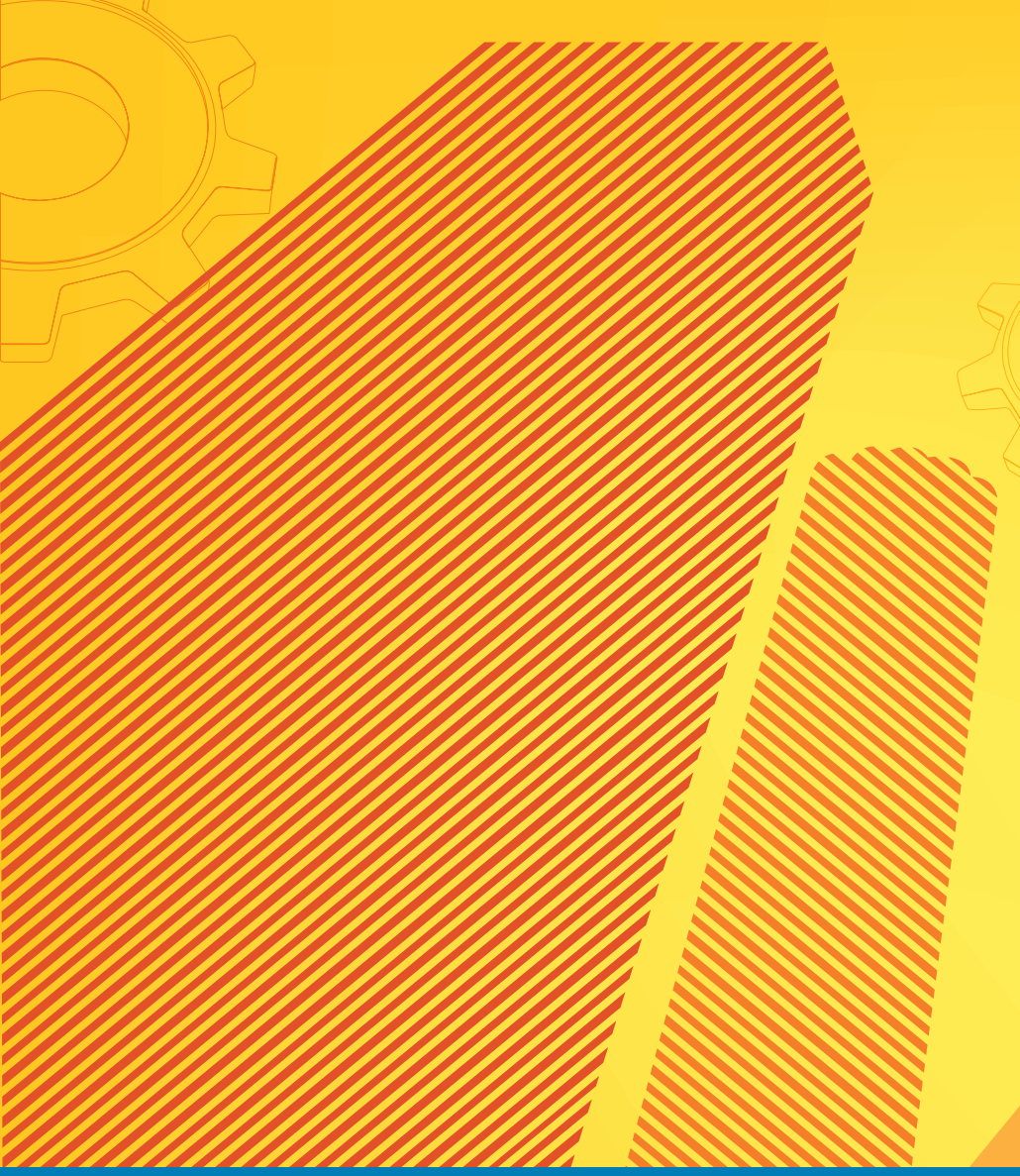




\section{PROCEEDINGS OF THE GREATER MEKONG SUBREGION URBAN DEVELOPMENT AND PLANNING TRAINING PROGRAM}

11-15 May 2015

Tengchong, Yunnan, People's Republic of China 
(C) 2017 Asian Development Bank

6 ADB Avenue, Mandaluyong City, 1550 Metro Manila, Philippines

Tel +632632 4444; Fax +6326362444

www.adb.org

Some rights reserved. Published in 2017

Printed in the Philippines.

ISBN 978-92-9257-689-9 (Print), 978-92-9257-690-5 (e-ISBN)

Publication Stock No. RPT168581-2

DOI: http://dx.doi.org/10.22617/RPT168581-2

The views expressed in this publication are those of the authors and do not necessarily reflect the views and policies of the Asian Development Bank (ADB) or its Board of Governors or the governments they represent.

ADB does not guarantee the accuracy of the data included in this publication and accepts no responsibility for any consequence of their use. The mention of specific companies or products of manufacturers does not imply that they are endorsed or recommended by ADB in preference to others of a similar nature that are not mentioned.

By making any designation of or reference to a particular territory or geographic area, or by using the term "country" in this document, ADB does not intend to make any judgments as to the legal or other status of any territory or area.

This work is available under the Creative Commons Attribution 3.0 IGO license (CC BY 3.0 IGO)

https://creativecommons.org/licenses/by/3.0/igo/. By using the content of this publication, you agree to be bound by the terms of this license. For attribution, translations, adaptations, and permissions, please read the provisions and terms of use at https://www.adb.org/terms-use\#openaccess

This CC license does not apply to non-ADB copyright materials in this publication. If the material is attributed to another source, please contact the copyright owner or publisher of that source for permission to reproduce it. ADB cannot be held liable for any claims that arise as a result of your use of the material.

Please contact pubsmarketing@adb.org if you have questions or comments with respect to content, or if you wish to obtain copyright permission for your intended use that does not fall within these terms, or for permission to use the ADB logo.

Notes:

In this publication, "\$” refers to US dollars.

ADB recognizes "China" as the People's Republic of China.

Corrigenda to ADB publications may be found at http://www.adb.org/publications/corrigenda 


\section{Contents}

Foreword iv

Acknowledgments vi

Overview vii

$\begin{array}{lr}\text { Training Highlights } & 1\end{array}$

Session 1: The Rural-Urban Physical Planning Framework 1

Session 2: Master Planning, Urban Design, and Current Trends in International Planning 3

Session 3: Developing Sustainable, Resilient, Climate Change Mitigation Cities 6

Session 4: Key Issues In Urban Planning: Civil Infrastructure Delivery (Engineering), Housing, and Heritage Preservation 9

Session 5: Special Economic Zones 12

Summary Session: Emerging Planning Practice in the People's Republic of China $\begin{array}{ll}\text { and Country Presentations } & 14\end{array}$ 


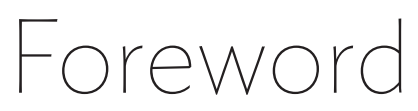

n 2012, the Asian Development Bank (ADB) and the Government of the People's Republic of China (PRC) jointly launched the Regional Knowledge Sharing Initiative (RKSI) to promote and facilitate knowledge sharing among ADB's developing member countries (DMCs). Such knowledge cooperation is expected to contribute to the promotion of more effective and sustainable development practices as well as to the advancement of regional cooperation and integration. Since its inception, the RKSI had supported 16 knowledge sharing events by mid-2015 through design and implementation assistance and financial contributions. Those knowledge sharing events addressed a wide range of vital development issues, notably renewable energy, climate change, air quality, social development, inclusive growth, innovation, vocational training, public financial management, and public-private partnerships. Highlights of those events included the PRC's experience in dealing with such issues, and good international practices and the experience of other DMCs.

This report summarizes a 5-day training program on the PRC's experience in urban development and planning, for the benefit of key officials of the six countries of the Greater Mekong Subregion (GMS) - Cambodia, the PRC, the Lao People's Democratic Republic, Myanmar, Thailand, and Viet Nam. The training program, which was held on 11-15 May 2015 in Tengchong, Yunnan Province, PRC, was jointly organized by ADB, and the Ministry of Finance and the Ministry of Housing and Urban-Rural Development of the PRC. The city administration of Tengchong provided strong support.

The training program addressed core issues of vital interest to all GMS countries. It is actually recognized, however, that these issues are not necessarily unique to GMS countries: in fact, they are relevant to most, if not all, developing countries in Asia.

Urban areas are home to almost half of Asia's population, and half the world's megacities are in Asia. Currently, Asia's urban population is increasing by some 44 million each year. Urbanization is a critical dimension of development. The speed and scale of urbanization in the PRC has been extraordinary, facilitating industrialization, economies of scale, and the pooling of labor skills. However, serious problems have been encountered, including environmental degradation, the inadequacy of municipal and social services, and inequality in standards of living.

Guided by distinguished international and national experts, the training program explored how to promote the development of cities as human-centered, competitive, and environmentally attractive urban centers. The following themes were comprehensively reviewed:

(i) The PRC's Urban-Rural Physical Planning Framework;

(ii) Master Planning in the PRC;

(iii) The Evolution of Building and Urban Design in the PRC;

(iv) Emergence of International Urban Planning "Best" Practices; 
(v) Urban Sustainability and Resilience;

(vi) The Relationship between Urban Form and Energy Consumption, Pollution, and Greenhouse Gas Emissions;

(vii) Delivery of Urban Infrastructure in the PRC;

(viii) Heritage and Cultural Preservation Planning;

(ix) Housing Policy in the PRC; and

(x) The Role of Special Economic Zones in the PRC's Urbanization and Economic Development Process.

The PRC's urban development experience over the last 35 years provided an interesting case study. This, together with a thorough review of international good practices and sharing of the experiences of the other GMS countries, provided highly useful guidance for more effective urban planning in the GMS countries and other DMCs.

Master plans that reduce the carbon and urban footprints and the congestion and pollution due to uncoordinated urban growth are required. The policies and decisions made now on urban development and natural resource management will have profound implications for social and economic development far into the future. As summarized in this report, during the training program, experts from the PRC outlined the country's new urbanization policies, laws, and regulations related to urban and rural planning and management. More specifically, they detailed the PRC's approaches to master planning, infrastructure planning, design of district and industrial areas, housing, historical and cultural city conservation, and scenic area planning. In turn, international experts outlined good or "best" practices in promoting livable, competitive, and environmentally attractive urban centers. In particular, the international experts stressed compact spatial planning and transit-oriented development.

This report provides insight to key urban development questions. How can we maintain vital economic growth while creating livable cities for an increasingly urban population? How can we manage urban density through master planning? How can we best integrate rural-urban development? How can the environmental and ecological footprints of cities be reduced? How can urban planning contribute to more inclusive growth?

In the interest of promoting knowledge sharing among developing countries, ADB, together with the Government of the People's Republic of China, is publishing the proceedings of the 5-day training session on urban development and planning, with the hope that the subject matters discussed during the event may be of interest and use to experts in GMS countries who could not join the event, as well as those in much wider regional and international professional communities.

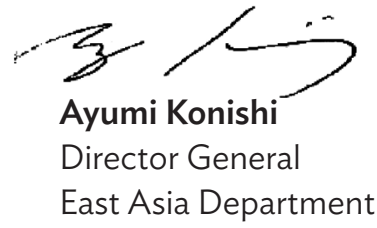




\section{Acknowledgments}

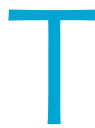

his report documents the experiences, views, and lessons shared during the 2015 Regional Knowledge Sharing Initiative (RKSI) flagship event: the Greater Mekong Subregion (GMS) Urban Development and Planning Training Program, held in Tengchong, Yunnan, People's Republic of China (PRC), on 11-15 May. We thank all participants from Cambodia, the PRC, the Lao People's Democratic Republic, Myanmar, Thailand, and Viet Nam for their experience sharing and discussions.

We would like to thank the Ministry of Finance and the Ministry of Housing and Urban-Rural Development of the PRC, under the guidance of Zhao Yongge, for coorganizing this training. We are grateful to the China Academy of Urban Planning and Design (under the guidance of Jing Feng) for their assistance in identifying resource persons and to the Yunnan provincial government for logistical support. The training program is also an outcome of effective collaboration within the Asian Development Bank. The six resident missions in the GMS countries assisted in government official nominations and made travel arrangements for participants. We also thank Douglas Webster, professor of East Asian Urbanization at Arizona State University, and Alexandra Vogl, urban development specialist, Sustainable Development and Climate Change Department, for their contribution to program design and Xin Zhang, knowledge sharing and service coordinator, RKSI, for efficient workshop coordination.

Douglas Webster prepared this report under the guidance of Fei Yu, head of RKSI. We are grateful for the review and comments of the Ministry of Finance and the Ministry of Housing and UrbanRural Development of the PRC. 


\section{Overview}

\section{Background}

Urbanization, which creates both significant opportunities and challenges, is a leading issue facing many of the Greater Mekong Subregion (GMS) countries, despite wide variation in each member's position on the urbanization trajectory/rural-urban transition. The People's Republic of China (PRC) has benefited greatly from its path-breaking early commitment among developing countries to accelerated productive urbanization, particularly in terms of economic growth and poverty reduction. While rapid urbanization in the PRC has spurred introduction at scale of high impact urban technologies ranging from saturation mass transit and high-speed rail, it has also resulted in massive challenges particularly related to air quality.

Given the likely benefits from GMS countries' exploring the PRC urbanization process and the institutional frameworks supporting the process in depth, as a catalyst to discourse on best practice urban development paths forward, the Asian Development Bank (ADB) and the Ministry of Finance and the Ministry of Housing and Urban-Rural Development of the PRC convened the Greater Mekong Subregion Urban Development and Planning Training Program, in Tengchong, Yunnan, PRC, on 11-15 May 2015. The Regional Knowledge Sharing Initiative, a joint initiative between the PRC and ADB, supported and organized the event.

The objective of the workshop was to use the PRC's vast and effective urbanization process over the last 35 years as a catalyst to explore best urban development practices applicable to the GMS countries. The event combined formal presentations, expert commentary, and discussion among all participants, who brought their own urban development experiences to the workshop.

Eighteen delegates from the six member GMS countries participated, plus speakers, moderators, and support staff. Leading faculty of the China Academy of Urban Planning and Design delivered the majority of presentations. Alexandra Vogl, urban development specialist at ADB, and Douglas Webster, professor of East Asian Urbanization at Arizona State University, moderated sessions and facilitated discussions and group dynamics.

\section{Themes}

In the opening session, ADB stressed the need for competitive, inclusive, and green urbanization. The fast pace of urbanization in the PRC was highlighted: in 1980, at the beginning of the reform period, the PRC was less than $20 \%$ urbanized; in 2015, the country's urbanization level reached $55 \%$. The increasingly important role of urbanization in developing the PRC's interior, significantly driven by the movement of manufacturing from the coast, was noted as an opportunity to put learning from earlier coastal urbanization into practice. 
Delegates were introduced to an interesting geographic factum familiar to every student in the PRC: the country is divided into north and south quadrants by a line running from Tengchong, the site of the workshop, to Heihe in northeast PRC's Heilongjiang Province. National representatives stressed the growing interaction between southwest PRC and Southeast and South Asia, expressed in many dimensions from energy flows to transportation corridors.

The deputy mayor of Tengchong County warmly welcomed the delegates, explaining that Tengchong is a historic business center, long known for its trade with Southeast Asia, and as a key trading post on the southern Silk Road. With an urbanization level of $40 \%$, Tengchong wants to apply best urban practices, particularly related to infrastructure and sustainability, as it continues to urbanize, driven by its strategic position on the New Silk Road, and its many scenic attractions.

Main themes comprehensively presented and discussed over the 5-day workshop were (i) The PRC's Urban-Rural Physical Planning Framework; (ii) Master Planning in the PRC; (iii) The Evolution of Building and Urban Design in the PRC since the Mid-20th Century; (iv) Emergence of International Urban Planning Best Practice; (v) Urban Sustainability and Resilience; (vi) The Relationship between Urban Form and Energy Consumption, Pollution, and Greenhouse Gas (GHG) Emissions; (vii) Delivery of Urban Infrastructure in the PRC; (viii) Heritage and Cultural Preservation Planning; (ix) Housing Policy in the PRC; and (x) The Role of Special Economic Zones in the PRC's Urbanization and Economic Development Process. The last module of the workshop summarized the week's learning from the PRC urban development experience, and put forward emerging challenges that the PRC's urban development system will face as the country pursues a modern services, "designed in (the People's Republic of) China," high-value economy.

\section{Objective}

Use the PRC's urbanization experience over the last 35 years as a case study to share urban development good practices and lessons with the GMS countries.

\section{Participants}

More than 30 senior urban development and planning officials from 6 GMS countries (Cambodia, the PRC, the Lao People's Democratic Republic, Myanmar, Thailand, and Viet Nam) participated.

\section{Scope}

The course comprehensively reviewed the PRC's urban development experience in terms of (i) multiscale urban physical planning system, (ii) master planning, (iii) evolution of building and urban design, (iv) housing policy, (v) sustainability and resilience, (vi) heritage and cultural preservation, (vii) civil infrastructure, and (viii) special economic zones in the context of (a) international best urban development practice; (b) ADB's competitive, inclusive, green paradigm; and (c) efficient energy conserving, pollution/GHG reducing urbanization. 


\section{Context: Urbanization Challenges in the People's Republic of China}

The workshop's comprehensive overview of the PRC's physical urban development system and experiences was timely in that the country is undergoing the most significant economic and built environment structural changes since market reforms were introduced in the early 1980s. Over the last 35 years, it has successfully put in place more housing, and urban and interurban infrastructure than any country in world history. Quantitative needs have largely been met, given that the rural-urban transition is approximately two-thirds complete in the PRC, and urban growth rates will slow significantly. The country's urban challenge moving forward is to put more emphasis on the quality of urban environments and communities, and to create the new urban spaces needed to support a high value-added economy. In 2013, the PRC transitioned from being a predominantly manufacturing economy ("factory of the world") to a predominantly modern services economy. This will evoke profound changes in its cities, with more spatial emphasis on core urban areas; development of urban platforms, such as smart cities, to support innovation; and increased demand for high-quality communities and housing from an increasingly affluent citizenry.

\section{Evaluation}

Evaluation shows an overall satisfaction rate of $95.4 \%$. All participants (100\%) perceived the trainers as well-prepared, and the training objective as clearly met; they deemed the training useful for their future work. Participants showed great interest in the PRC's best practice and site visits, and were enthusiastic about sharing experiences and lessons among GMS countries. As a result of the training, participants hoped to improve their future work and apply experiences and lessons to their own countries by including innovative features in the urban comprehensive plan. Further topics they would be interested in are special economic zone development and environmental protection, private partnership in urbanization, practices in other developing countries, climate change adaptation and mitigation for urban development process and poverty reduction.

\section{Link for additional information}

http://www.rksi.org/event/gms-urban-development-planning-training-program

\section{Key Workshop Takeaways}

Key areas in which the urbanization process in the PRC can provide valuable learning are as follows:

(i) Large-scale fast (less than two generations) economic, employment creation, and poverty alleviation benefits can be achieved when there is a societal commitment to accelerated productive urbanization, and resources are allocated and deployed to support the process. 
(ii) Large-scale investment in mass transit (subways, light-rail transit)in metropolitan regions, with a goal of saturation mass transit, enables high-density development consistent with high accessibility. Benefits include lower pollution and energy consumption, lower GHG emissions, and reduced travel time.

(iii) The PRC has developed three massive megapolitan regions (the Pearl River Delta, the Yangtze Delta, and Beijing-Tianjin-Hebei) all with over 50 million residents. These megapolitan regions are composed of interconnected metropolitan regions, indicating that supra-large-scale urbanization is feasible and productive, if appropriate infrastructure is put in place.

(iv) Introduction of high-speed rail (HSR) systems connecting key urban centers enables metropolitan regions to specialize, in many cases, within larger megapolitan regions. HSR stations are driving new urban centers in the PRC metropolitan regions such as Hongqiao in Shanghai.

(v) Urban special economic zones, including economic and technological development zones and high-tech industrial development zones, have played a significant role in the rapid economic development in the PRC. Such industrial zones enable economic and geographic clustering of firms, and have higher environmental performance than freestanding factories.

(vi) The PRC's attempts to deliver affordable housing illustrate the complexity of the challenge, and the need for authorities to support commercial delivery of housing, along with subsidization to enable delivery of affordable housing to lower-income groups through mechanisms such as subsidized land costs and within project crosssubsidies by developers.

(vii) Urban development stakeholders in the PRC are placing increasing emphasis on protection of heritage and cultural resources, a movement that has gained considerable momentum over the last 15 years. A number of mechanisms are being developed, based on comprehensive national inventories of built heritage, to protect built heritage in the context of rapid urbanization.

(viii) The PRC is beginning to recognize that tourism and amenity seeking are increasingly important drivers of urban development, with urban development agencies such as the Ministry of Housing and Urban-Rural Development (MOHURD) and the China Academy of Urban Planning and Design (CAUPD) developing new planning approaches geared to this fast emerging urban driver. This includes new instruments, e.g., ecolines, designed to protect areas of high scenic and environmental services value. 


\section{Training Highlights}

\section{SESSION1 \\ The Rural-Urban Physical Planning Framework}

This session laid the framework for the workshop, providing a comprehensive outline of the development of urban development and planning processes in the People's Republic of China (PRC), and a detailed review of the institutional structures supporting the development of urban places in the PRC.

Moderator: Douglas Webster

Professor of East Asian Urbanization, Arizona State University, United States

The People's Republic of China's Urban-Rural Development and Planning Working System Zhang Bing

Chief Planner, China Academy of Urban Planning and Design (CAUPD)

Implementation of Urban Planning, Management Systems, and Regulations

Dong Ke

Vice Director of Research Department of Urban and Rural Planning, CAUPD

The People's Republic of China's Urban-Rural Development and Planning Working System

Zhang Bing

Chief Planner, China Academy of Urban Planning and Design (CAUPD)

Summary

The presentation stressed the dynamism and adaptiveness of the PRC planning system. Zhang Bing indicated that modern PRC city planning started with industrial planning in the 1950 s, industry being the national priority at that time. More balanced urbanization was pursued after 1978; the pace of urbanization accelerated in the mid-1990s, guided by the City Planning Act of 1990. The 1994 Decentralization reform that provided local governments with more revenue and policy latitude stimulated local governments to act more assertively while creating competition among cities. The Urban and Rural Planning Act of 2008 updated the city planning system while promoting balanced and linked urban-rural development. The national planning agency - the National Development Reform Commission (NDRC)-has led regional development planning efforts in the PRC, complementing the physical planning role of the Ministry of Housing and Urban-Rural Development (MOHURD). In 2012, the NDRC instituted the concept of macrofunctional zones, e.g., agricultural, urban, and ecological. 
Key Points

1. The national government and its political priorities significantly affect urban policy and urbanization on the ground. Urbanization was steady during the 1949-1957 industrial push, and then stagnated during the Great Leap Forward and Cultural Revolution periods. With the economic reform starting in 1978, urbanization has been rapid: urbanization level rose from $17.9 \%$ of the PRC's population in 1978 to $55 \%$ in 2015 , supporting rapid poverty reduction and rapid increases in gross domestic product (GDP). (The PRC's GDP per capita in 2014 was $\$ 7,485$.)

2. Urbanization is currently focused on three megapolitan regions - the Pearl River Delta, the Yangtze Delta, and the Beijing-Tianjin-Hebei areas. These areas account for only $3.4 \%$ of the PRC's total land area, but $13.5 \%$ of its population, and $37.8 \%$ of its GDP, which means that the average worker is about three times as productive in these megapolitan regions as in the PRC as a whole, as a result of talent attraction, and agglomeration and localization of economies.

3. Tourism and amenity are becoming an important driver of urbanization, as recognized by MOHURD. The development of many cities, including Guilin, Hangzhou, Lijiang, and Sanya, is driven by tourism and amenity dynamics.

4. As is the case in most of the world, large swaths of rural areas in the PRC are losing population, and small villages are disappearing - approximately 0.9 million from 2000 to 2010 .

5. Although the decentralization initiatives of 1994 improved the fiscal position of cities, they remain highly dependent on land sales revenue (approximately 25\% of total municipal revenues). Approximately $60 \%$ of land sales revenue is reinvested in infrastructure locally.

\section{Implementation of Urban Planning, Management Systems, and Regulations}

\section{Dong Ke}

Vice Director of Research Department of Urban and Rural Planning, CAUPD

\section{Summary}

The presenter outlined the PRC's urban and regional planning system, based on the Urban and Rural Planning Law of 2008, in detail. He indicated that the basis of the system is "one note, two permits." To undertake urban construction in the PRC, a "locational permission" must be acquired from the local government (normally the Planning Bureau), based on acquisition of the two permits. One required permit is the "development permit," which indicates land use, overall building mass, etc., and is consistent with the detailed plan. The other is the "building permit," which indicates that the building meets construction and safety standards, etc. The master plan of a city covers the city planning area, i.e., built-up areas and areas that may be subject to city building over the course of the plan. The master plan is, in turn, divided into detailed plans; a large city may have over 100 detailed planning areas. Local authorities will generally pay special attention to areas of intensive development and redevelopment or areas being newly opened up. The detailed planning areas indicate technical regulations that must be adhered to such as 
floor area ratios, building height, parking, allocation of land for public use (such as school sites and neighborhood parks), and restrictive conditions regarding its use. In addition, guidelines may be included, e.g., architectural style guidelines. Thus, the locational note essentially assures consistency with the detailed plan for the site in question.

\section{Key Points}

1. The PRC's master planning system is significantly derived from the British system, relying on a hierarchy of master and detailed plans, with regulation playing a key role. It is a hierarchical system, whereby all plans must be approved by higher-level authorities, e.g., an urban district master plan must be approved by the municipal government..

2. In urban areas in the PRC, the state owns all land but leases land for private development, normally 70 years for residential use, and 40 years for commercial. When land is leased or transferred among private parties (the secondary market), the locational note system described earlier comes into effect.

3. As cities in the PRC become more affluent and urban residents become more demanding regarding community quality, there will be pressure to adapt the planning system, to pay more attention to regulation as well as to the aesthetic quality of development.

\section{Master Planning, Urban Design, and Current Trends in International Planning}

This session focused in more detail on master planning in the PRC, and international trends that are likely to impact PRC urban planning, including master planning, in the foreseeable future.

Moderators: Douglas Webster

Professor of East Asian Urbanization, Arizona State University

Alexandra Vogl

Urban Development Specialist, Asian Development Bank (ADB)

Urban Master Planning

Zhang Juan

Chief Engineer, Institute of Urban Planning and Construction, CAUPD

Architecture Design in the People's Republic of China: The Last Four Decades

Zhang Junying

Director of Design Consulting and Management Center, China Architecture Design Institute

\section{Current Trends in International Planning \\ Douglas Webster}

Professor of East Asian Urbanization, Arizona State University 


\section{Urban Master Planning}

\section{Zhang Juan}

Chief Engineer, Institute of Urban Planning and Construction, CAUPD

\section{Summary}

The presentation focused on the master planning process at three spatial levels where it is applied in the PRC: city, town, and village. Inputs to the plan making, which is the responsibility of local planning bureaus at all levels, are from the political arena (National People's Congress), expert opinion, and public opinion. At the city level, the master plan is prepared for the planning area, which is usually considerably smaller than the municipality encompassing the current built-up area, plus the area expected to be built up over the planning period. Identifying urban planning areas is necessary because municipalities considerably overbound actual urbanization, especially in western PRC. Central cities (the core city) are recognized as special areas in many cases, receiving more detailed treatment in detailed plans, as discussed in Session 1. Master plan preparation relies highly on standards produced by the MOHURD, and the technical plan preparation is usually undertaken by urban design institutes that are affiliated with the planning bureaus at the municipal and higher levels of government. County planning, for major county towns (there are usually at least 10 towns in a county), are prepared using a scaled-down process similar to the City Planning Master Planning process. Village master planning has been upgraded after the passing of the Villagers Autonomous Law of 2010, which reflected key tenets of the New Socialist Countryside Movement introduced in 2005. Accordingly, current village planning stresses protecting the traditional appearance of villages, improvement of the village environment, and augmenting the village economic base through agricultural and tourist (often agri-tourism) development.

\section{Key Points}

1. The PRC's approach to master planning relies heavily on standards, e.g., road width, green space per population, dimensions of public spaces.

2. An important innovation in master planning has been the use of color lines, which forbid certain land uses within the color lines. For example, color lines protect ecological areas (ecolines) historical and archeological areas, scenic areas (used in plotting transportation corridors), and disaster areas (floodplains, etc.). It uses a layering system that identifies different land-use systems, e.g., transport, industrial, functional (e.g., urban subcenters), utilities, enabling use of the color lines system.

3. As noted, the PRC's approach to master planning relies highly on public design institutes, which means limited involvement of private sector urban planning firms in city planning, unlike at the building scale where the majority of architecture firms are privately owned.

4. As in the MOHURD, there is increasing awareness of the value of tourism and heritage preservation at the city (Urban Planning Bureau) level. This is reflected in the fact that Guilin was designated as the PRC's first national historic and tourism city and national tourism pilot area in 2010, with the master plan driven by that role, and by the new emphasis on protection of traditional appearance at the village level, and development of agri-tourism. 


\section{Architecture Design in the People's Republic of China: The Last Four Decades Zhang Junying}

Director of Design Consulting and Management Center, China Architecture Design Institute

\section{Summary}

This presentation focused on the design history of major buildings in the PRC since 1949 that affected their surroundings (urban design) and urban design practice across the country. Early buildings, such as the Beijing Hotel and the Beijing Capital International Airport Terminal, were designed to project the PRC's reemergence on the world stage, reflecting international functionalist style. The subsequent Beijing Railway Station reflected a movement toward building design with Chinese architecture characteristics. In the 1980s, a movement toward collaboration with foreign architects, e.g., I. M. Pei, and, by the 1990s, a full embrace of modernism not only in building design but at the city planning scale reflected in wide monumental avenues, massive building scale, super blocks, etc., reflected most clearly in the development of Lujiazui, Shanghai's 28 square kilometer financial center. Of late, in the PRC, there has been a movement toward architectural innovation reflected in an emerging postmodern style, e.g., the Baidu headquarters building in Beijing, the Chongqing Art Center, the China Pavilion at the 2010 Shanghai World Expo, and the Suzhou HSR Station; and a parallel, sometimes overlapping movement associated with reconnection to local Chinese motifs, e.g., the Lhasa Railway Station in the Tibet Autonomous Region of the PRC.

\section{Key Points}

1. Much of the built form of cities is modernist, reflecting the peak of urban building boom in the PRC from the mid-1990s to 2008, which coincided with the PRC's embrace of this style.

2. Urban design from 1949 to the present has evolved significantly, from an early international functional style, to Soviet realism with Chinese architecture characteristics, to modernism, to a current style that reflects both architectural innovation and vernacular architecture in the PRC.

3. The architecture profession is becoming increasingly privatized and globalized in the PRC, with more than $50 \%$ of firms now privatized, including the dominant China Architecture Design Institute, which recently acquired CPG, the largest Singapore architectural practice. Conversely, international firms, such as SOM, have had a long presence in the PRC. This globalization is reflected in the wide variety of building styles in cities in the PRC, and the tendency for rapid change in design fashion.

\section{Current Trends in International Planning}

\section{Douglas Webster}

Professor of East Asian Urbanization, Arizona State University

\section{Summary}

This presentation highlighted the fact that planning practice is becoming increasingly globalized, with a core of "best practice" emerging. This widespread rapid diffusion of knowledge is generally 
positive, but the risk is that diversity in planning thought may be threatened. Emerging best practice themes discussed included (i) Smart Cities; (ii) New Urbanism; (iii) Transit-Oriented Development (TOD); (iv) Airport Zones ("Aerotropolis"); (v) Amenity and Tourism-Based Development; (vi) The Creative Economy; (vii) New Forms of Land-Use Guidance, particularly Form-Based Land-Use Planning; (viii) Urban Sustainability, encompassing Conventional Pollution, Greenhouse Gas (GHG) Emissions, and Alternative Energy; and (ix) Heritage and Cultural Preservation and Planning.

\section{Key Points}

1. As the PRC's economy changes from a peri-urban-centered manufacturing economy to an urban core center modern services economy, and urban residents become more demanding in terms of the quality of the urban environment, the PRC's planning framework structures will need to be revisited and revised. For example, in master planning, there will be less need for focusing on nuisance activities (e.g., polluting industries) and more need to focus on the "on the ground" quality of life, e.g., walkability, street-front activity. As the country undergoes this transition, there is much to be learned from global best practice, particularly related to the areas discussed in the presentation.

2. In the PRC's city planning should foresee emerging urban technologies as accurately as possible, e.g., the implications of driverless cars (which will be widespread within 20 years) on urban form and infrastructure.

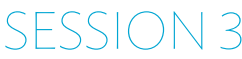

\section{Developing Sustainable, Resilient, Climate Change Mitigation Cities}

This session focused on the importance of developing resource-conserving, sustainable, and resilient cities. Improvements in the performance of cities in the PRC in regard to energy efficiency, lessened conventional air pollution, and lower GHG emissions (areas where progress is being made) will contribute significantly to the quality of life of the PRC's urban residents, and global society as a whole.

\section{Moderator: Douglas Webster}

Professor of East Asian Urbanization, Arizona State University

Smart and Resilient Urban Development for Green, Inclusive, and Competitive Cities Alexandra Vogl

Urban Development Specialist, ADB

A Framework to Facilitate Compact Spatial Planning and Transit-Oriented Development Policies for Climate Change Mitigation in the People's Republic of China

\section{Serge Salat}

International Urban Planning Consultant 


\section{Smart and Resilient Urban Development for Green, Inclusive,} and Competitive Cities

\section{Alexandra Vogl}

Urban Development Specialist, ADB

\section{Summary}

The presentation laid out ADB's mission to support competitive, inclusive, green cities, and the increasing importance that $A D B$ places on urban issues, expenditure on which constituted $\$ 1.7$ billion of ADB's $\$ 22$ billion operational budget in 2014 . The presentation emphasized the key role of sound financial practices in city development; the need to selectively incorporate "smart" technologies into urban programming; and the importance that should be accorded to developing resilient cities based on knowledge, investment, and collaboration among development partners. Urban resilience was defined as the capacity of individuals, communities, institutions, businesses and systems in cities to survive, adapt, and grow in the face of stress and shocks induced by climate change. Two threats facing cities in Asia, including those in the PRC, were emphasized: (i) air pollution$65 \%$ of urban air pollution mortality occurs in Asia, and (ii) sea-level rise and flooding associated with climate change. Sea-level rise could result in $\$ 55$ billion annually in damages from 2010 to 2050 (the Bangkok flood in 2011 caused $\$ 40$ billion in global damages).

\section{Key Points}

1. ADB's operational plan focuses on secondary cities with populations in the range of 250,000 to 500,000 . Such cities are often overlooked in terms of support to apply best urban development practice.

2. The importance of smart city information and communication technology platforms was emphasized. Such platforms are needed to support mobile devices, the internet of things, and sensor-monitoring smart city management systems (e.g., irrigation, traffic, parking, waste disposal) yielding benefits in terms of competitiveness, innovation, effectiveness of local governance, efficient energy and natural resource consumption, etc.

3. The importance of sound innovative urban finance, including urban fiscal decentralization, was emphasized. Particularly important are (i) improving local revenue generation, (ii) improving local creditworthiness, (iii) developing bankable projects, (iv) mobilizing public-private partnerships, and ( $v$ ) providing confidence to private sector investors.

ADB. 2014. Urban Climate Change Resilience: A Synopsis. Manila. https://www.adb.org/publications/urban-climate -change-resilience-synopsis 


\section{A Framework to Facilitate Compact Spatial Planning and Transit-Oriented} Development Policies for Climate Change Mitigation in the People's Republic of China

\section{Serge Salat}

International Urban Planning Consultant

\section{Summary}

The presentation emphasized the importance of compact, transit-oriented development (TOD). To maximize the value of development based on TOD, it is important that the distribution and hierarchy of density be carefully guided within metropolitan regions; otherwise, investment in mass transit will yield suboptimal returns. Hong Kong, China was put forward as a best practice case, where $43 \%$ of the population and $83 \%$ of jobs are located within 500 kilometers of a mass transit station. The presentation pointed out that the richest cities in the world often have low levels of car ownership, e.g., there are only 56 cars per 1,000 people in Hong Kong, China while in Manhattan, only $20 \%$ of households own a car-these are targets that the PRC can aspire to.

The presenter indicated that if you focus on developing land rather than the urban economy you are in danger of generating negative marginal economic returns from spread, leap-frogging city building. (The more you develop land, the less you develop the economy.) In the PRC, cities such as Chongqing fall into this category. Thus, there is a need for more contiguous, compact development, structured around hierarchical nodes, if the PRC is not to lose its traditional advantage associated with high urban densities.

Key nodes in the urban fabric, especially central business districts, produce great value, e.g., $20 \%$ of London's area produces $80 \%$ of its GDP. Thus, areas of concentrated jobs are important, e.g., New York has 152,000 jobs per square kilometer at its peak; London, 142,000; and Hong Kong, China, 120,000. Such areas require special attention in terms of their development.

\section{Key Points}

1. The PRC should increase the connectivity of its mass transit systems, i.e., there should be more connection points.

2. The PRC should focus on developing its urban economies, not its urban land. This would require reform of the current urban fiscal system in the country, which is highly dependent on land sales for revenue, creating incentives for spread development.

3. Because cities grow exponentially as they spread outward, saturation transit makes sense for the core, but peripheral development should be corridor in form.

4. The distribution of urban density matters considerably in terms of energy efficiency, minimization of travel times, and pollution and GHG reduction. High densities alone do not constitute a smart city; the pattern of density is equally important. In the PRC, most cities, including Shanghai, are too flat in terms of their density patterns, i.e., there is not enough variation in density (nodality). 
5. The superblocks with "towers in the park" model of urban development, popular in many cities in the PRC, is especially to be avoided from an energy, pollution, travel efficiency, and livability perspective.

\section{SESSION 4 \\ Key Issues in Urban Planning: Civil Infrastructure Delivery (Engineering), Housing, and Heritage Preservation}

This session focused on three different important urban subsystems, key to achieving efficient, high-quality urbanization, namely infrastructure, housing, and heritage preservation.

\section{Moderator: Douglas Webster}

Professor of East Asian Urbanization, Arizona State University

\section{Civil Engineering Planning}

Hao Tianwen

Professional Senior Engineer, Institute of Urban Water and Engineering, CAUPD

Urban Housing Development Planning

Jiao Yixue

Director, Institute of Urban Planning and Housing, CAUPD

Historical and Cultural Preservation Planning

Zhang Guanghan

Professional Senior Urban Planner, CAUPD

\section{Civil Engineering Planning}

\section{Hao Tianwen}

Professional Senior Engineer, Institute of Urban Water and Engineering, CAUPD

\section{Summary}

The presenter comprehensively described the PRC's institutional system and procedures for delivery of urban civil infrastructure, which includes water supply, wastewater, energy, communications, solid waste, environmental protection, and disaster prevention and preparedness. In the PRC, district heating, which can be energy efficient, is also an important component of urban infrastructure. Environmental protection and disaster prevention and preparedness are becoming increasingly important engineering functions in urban PRC. It was stressed that careful planning and design of infrastructure systems can save a city considerable budget, as unit costs vary widely according to design criteria. Determining the existing situation, future need and demand, and the source of inputs such as water and energy is important in infrastructure delivery. 
Key Points

1. Good engineering saves money by lowering unit costs. (Studies in Hong Kong, China have shown that compact urban form and state-of-the-art infrastructure delivery can lower unit infrastructure costs by at least 15\%.)

2. Incineration is becoming increasingly feasible, and arguably necessary, for solid waste disposal in metropolitan areas, given that new incineration technologies are cleaner, often cogenerating power, and the PRC's high population densities make landfills increasingly subject to "not in my backyard" forces.

3. High voltage lines should be in corridors around cities or run through green vectors; passage through densely developed areas should be avoided.

4. Dual wastewater systems are now the norm in the PRC; single systems that combine wastewater and drainage result in untreated water entering water bodies during storms.

5. Energy mode split is difficult to forecast with rapid changes in the mix. In particular, natural gas consumption is likely to gain share for use in buildings, industrial processes, and vehicles (taxis, buses) as the PRC moves toward a cleaner energy mix.

6. To the extent possible, all communication systems should be combined in common underground tunnels.

7. Essentially, civil engineering practice in the PRC parallels global practice and standards; however, the rapid speed of implementation distinguishes the PRC from most other countries.

\section{Urban Housing Development Planning}

Jiao Yixue

Director, Institute of Urban Planning and Housing, CAUPD

\section{Summary}

The presenter comprehensively outlined the evolution of the housing delivery system in the PRC from 1978 to the present. From 1978 onward, housing reform was rapid. Existing public housing was privatized, and establishment and rapid growth of a commercial housing delivery system was encouraged; by 1998, public delivery and ownership of the housing stock had essentially ended. This was replaced by a system whereby: (i) The middle- and high-income groups were expected to purchase housing from private property developers at market prices. (ii) Housing for the lower-middle income groups was also provided through the private market; however, such housing was subsidized through mechanisms such as lower land prices to developers, and regulations requiring a certain percentage of affordable housing in each development (currently $30 \%$ in Beijing), essentially a cross-subsidy at the project level. (iii) Low rent apartments were made available for the low-income group by local governments. However, waiting lists were formed for categories (ii) and (iii). At the same time, in many cities, particularly the largest ones, housing became significantly less affordable as prices rose steeply. This led to the announcement 
of a new housing supply system whereby 36 million affordable subsidized housing units will be built from 2011 to 2015 for rent and sale.

\section{Key Points}

1. Urban PRC has had great success in increasing housing unit size. In 1978 , there was an average (mean) of 6.7 square meters of residential floor space per person; by 2013, this metric had increased to 32.9 square meters. As PRC's economy has grown rapidly, one of the obvious areas of benefit to most of the urban population has been improved urban housing, particularly in terms of space. This contrasts with other Asian places such as Japan; Hong Kong, China; and Seoul, Republic of Korea, where rapid economic growth has not translated into significant gains in housing space.

2. In the PRC and elsewhere, access to work is essential to housing delivery: a good house is of little value to a worker if household members cannot earn a livelihood. According to PRC surveys, access, cost, and amount of space are the three most desired housing characteristics. PRC planners and local governments need to provide more affordable housing that is accessible to employment, e.g., in TODs along transit corridors. In the PRC, as in most countries, much of the affordable housing stock is in peripheral urban areas, with substandard accessibility.

3. Migrants generally benefit most from rental housing because their place of residence is often not (yet) set, making purchase less viable (sometimes exacerbated by local registration [hukou] impediments to obtaining a mortgage). In Chongqing, where largescale rural-urban migration is occurring within the municipality, $40 \%$ of public housing is allocated to migrants.

\section{Historical and Cultural Preservation Planning \\ Zhang Guanghan \\ Professional Senior Urban Planner, CAUPD}

\section{Summary}

As with other aspects of urban development in the PRC, in fact more so, there have been significant changes in the value placed on built and intangible heritage in the PRC. Until the end of the Cultural Revolution (around 1977), there was an emphasis on the modern, the historical built environment being devalued. Although modernist architecture and city planning triumphed in the PRC in the late 20th century, there was growing parallel recognition within the country of the importance of its past, both tangible and intangible. In 1985, the PRC joined the International Convention Concerning the Protection of World Culture and Natural Heritage, and in 2008, strong and comprehensive regulations to protect historic towns and villages were introduced. The United Nations Educational, Scientific and Cultural Organization (UNESCO) has designated 50 world heritage sites in the PRC; of these, 35 are cultural heritage sites, 11 are natural heritage sites, and 4 are cultural and natural (mixed) sites, ranking the PRC second in the world. ${ }^{2}$ There are currently 125 national historic cities, predominantly in eastern PRC, plus over 
200 provincial-level historic cities. Consistent with the UNESCO typology, the preservation of the PRC's heritage recognizes both the tangible environment, e.g., Houmen Bridge in Beijing from the Ming Dynasty, and the intangible environment, e.g., regional cuisines, religious practices, Chinese opera.

\section{Key Points}

1. Key principles utilized in the preservation of urban cultural heritage in the PRC include (i) minimal intervention; (ii) protection of the continuity of local life (living culture); (iii) protection of the surrounding environment (buffer zones); (iv) not rebuilding nonexisting buildings; ( $v$ ) propping up structures in danger of irreversible damage in an obvious way, e.g., St. Paul's Cathedral in Macau, China; and (vi) putting utilities underground.

2. As described in Session 2, a color line system is used to protect certain areas of the city. This device (purple lines) is increasingly being used effectively to delineate historical areas for protection in cities in the PRC.

\section{SESSION 5}

\section{Special Economic Zones}

This session emphasized the important role that special economic zones, in their many variants, have played in industrialization, rapid economic development, and accelerated urbanization in the PRC. Shenzhen, as a case study, illustrates the evolution of such zones, from being an original "Open City" based on export processing to its role today as one of the country's leading innovative cities.

\section{Moderator: Douglas Webster} Professor of East Urbanization, Arizona State University

Planning and Management of New Towns, New Districts, and Development Zones (Including Cross-Border)

Liang Hao

Section Chief, Shenzhen Branch, CAUPD

\section{Experiences and Lessons of City Development in Shenzhen} Wang Zejian

Deputy President, Shenzhen Branch, CAUPD 


\section{Planning and Management of New Towns, New Districts, and Development Zones (Including Cross-Border) \\ Liang Hao \\ Section Chief, Shenzhen Branch, CAUPD}

\section{Summary}

The presenter described the evolution of different types of urban spaces in the PRC from 1949 to the present, again stressing the adaptive capacity of urbanization in the country. As was indicated in Session 1, the priority given to industrialization and manufacturing during 1949-1957 led to the development and expansion of satellite manufacturing towns around many large cities, based on the Soviet Union model. With the economic reforms beginning in the late 1970s, special economic zones, four initially, were designated and constructed along the south coast, including Shenzhen, which ultimately became the most successful. These export processing platforms attracted foreign direct investment, initially particularly from Hong Kong, China and Taipei,China, and flourished based on good industrial infrastructure; low-cost labor; and zonespecific tax (corporate and personal), tariff, and other incentives. In the 1990s, Pudong in Shanghai was developed, which was more complex in concept and construction: it included the Lujiazui economic zone, a new international airport, seaport, and state-of-the-art manufacturing and research platforms. When the PRC joined the World Trade Organization in 2001, a new set of urbanization drivers associated with globalization was unleashed in the country. In particular, Shenzhen evolved into a high-level city for innovation. In parallel, two special global events positioned cities in the PRC on the world stage: the Beijing Olympics in 2008 and the Shanghai World Expo in 2010 acted as drivers of new types of built form (including building design and urban design), saturation mass transit, and environmental improvement. We are now seeing the emergence of eco-/green cities, e.g., the Sino-Singapore Tianjin Eco-City in Binhai, Tianjin, and plans are under way for development of "smart cities," e.g., Taopu Smart City in Putuo District of Shanghai.

\section{Key Points}

1. As indicated throughout the workshop, the PRC's urban development priorities, trajectory, and style are driven significantly by economic factors, both domestic and global. The urban system responds quickly to produce new types of urban platforms and modules as needed to support economic restructuring.

2. The PRC experiments with new urban development approaches locally, e.g., the "open cities" on the south coast in the early 1980 s, before upscaling the experiments nationwide if the initiative is successful. 
Experiences and Lessons of City Development in Shenzhen

Wang Zejian

Deputy President, Shenzhen Branch, CAUPD

\section{Summary}

Although Shenzhen initially developed based on export processing (see preceding presentation summary), in 1986, the municipal leadership made a conscious decision to move up the urban value chain. Importantly, the 1986-2000 Shenzhen Master Plan advocated and catalyzed implementation of a highly efficient linear corridor urban structure punctuated by urban nodes or clusters. The 1986 plan also laid out important economic infrastructure such as new airport and container port facilities. High-quality residential development was emphasized to attract talent, abetted by a more flexible land-use policy than used elsewhere in the country. In 1986, Shenzhen constituted the PRC's first Planning Board as part of a statutory planning system, which requires approval of plans and major developments by relevant government departments, based on learning from Hong Kong, China. In 1989, Shenzhen explicitly indicated that it would pursue a high-value economy based on being a financial center (it is the site of one of the PRC's two stock markets), high-technology center, and center for advanced services. Shenzhen recognizes that it must be attractive to be a high-value urban economy, as such it has encouraged high-quality building and urban design. For example, the Shenzhen Development Center was the PRC's first super high-rise with a steel structure. Recognizing the importance of amenity in attracting talent, which is the source of innovation and economic growth, significant ecological areas are being protected based on the introduction of an eco control (color) line system, as discussed in Session 1. The PRC's metro system is being extended to 720 kilometers in recognition of the importance of rapid transit in alleviating pollution and GHG emissions, enhancing labor productivity, and supporting innovation.

\section{Key Points}

1. Shenzhen's Corridor and Cluster Master Plan is based on an urbanization pattern universally recognized as one of the most efficient from the perspective of energy, environmental quality, and travel time.

2. Shenzhen's urban development stakeholders, including its urban planners, are always open to adoption of new appropriate ideas from the outside.

3. Green space planning comprises state-of-the-art, east-west-connected vectors that run between the two main transport corridors. This type of green space planning does not constrain expansion of the city as greenbelts do (creating energy inefficient "jumping" over the greenbelt) and maximizes access to green space while enabling long distance walking, hiking, bicycling, etc.

4. Shenzhen prides itself on, and promotes, its role as a cosmopolitan city, benefiting from migration (domestic and foreign) and foreign investment.

5. Shenzhen promotes low-carbon development through building regulations, extensive metro construction, and adoption of urban form planning that minimizes carbon emissions. 


\section{SUMMARY SESSION}

\section{Emerging Planning Practice in the People's Republic of China and Country Presentations}

This session focused on two themes. Douglas Webster summarized the challenges facing urbanization stakeholders as the PRC enters a period of rapid economic development and urbanization. Country participants summarized learning from their knowledge of the PRC urban development and planning case, the subject of the week's deliberations.

\section{Moderators: Alexandra Vogl}

Urban Development Specialist, ADB

Douglas Webster

Professor of East Asian Urbanization, Arizona State University

Liang Hao

Section Chief, Shenzhen Branch, CAUPD

\section{The People's Republic of China's Emerging Urban Planning Practice:}

Opportunities and Challenges

\section{Douglas Webster}

Professor of East Asian Urbanization, Arizona State University

As the PRC embarks on a period of massive economic restructuring centered on "made in (the People's Republic of) China," modern services, talent attraction, and amenity, and a switch from quantity to quality in urban community development, it will need to update its planning processes and urban development practices. In this regard, it can benefit from emerging global best planning practice, particularly in regard to the following:

(i) Creation of world-class platforms to support the PRC's emerging modern service economy. This would include smart city platforms and communities that support innovation.

(ii) Higher-quality, human-centered residential communities that attract talent (including international talent), improve the quality of life, and support a more consumerdriven economy. These communities would be walkable, compact, transit-oriented development (TOD)-centered, mixed use, and vital, reflecting qualities seen in Shanghai's Cao Yang neighborhood, developed in the 1950s.

(iii) Improvements in TOD to enable higher returns on the massive investment in saturation mass transit systems in the PRC's major cities, manifest in higher property premiums in TOD areas, more efficient energy consumption, lessened conventional air pollution, reduced GHG emissions, and less human time wastage through unnecessary commuting times and travel for noncommuting reasons, e.g., to school, health care, shopping. 
(iv) Accelerated protection of built heritage resources in the PRC. Not only would this provide the youth with links to the past, but in a postindustrial economy, it would provide large-scale economic returns, as the case of Singapore illustrates (which did a 180-degree policy switch over two generations from destroying its built heritage to protecting it).

(v) Recognition that high amenity areas based on climate, scenery, urban design, services, cuisine, etc., will attract a disproportionate share of future migrants, especially talent, and built environment investment, driving the economy of such areas. The environmental quality of these areas should be improved, while accepting the reality of fast future demographic and built environment growth - a very tough challenge.

(vi) Accelerated reduction in conventional air pollution, the greatest urban environment threat to public health in the PRC, based on the successes of global cities, including Bangkok, London, and Los Angeles.

\section{Learning from the People's Republic of China}

\section{Country Presentations}

Countries participating in the workshop indicated that they benefited from exposure to the PRC urban planning and development model in the following key ways:

\section{Cambodia}

1. Bold initiatives such as the national economic reform policy in the early 1980s, which resulted in "opening up" and the designation of "open cities."

2. Formulation of clear urban and rural planning policies and frameworks.

3. Enforcement of the urban planning system, based on monitoring.

4. Follow-up evaluation of the implementation of master plans.

5. Support to architectural innovation, and historical and cultural preservation.

6. Increased concern with green urban development, including creation of resilient cities.

7. Increased concern with support to TOD, and compact urban development.

8. Evolution of housing policies to address the issue of housing affordability.

9. Increased concern with the relationship between tourism, amenity, and urban development. 


\section{People's Republic of China}

1. Environmental problems in cities in the PRC are becoming more serious, and need to be immediately addressed.

2. Old buildings, built before and during the early stages of the reform period (after 1980), are aging and need to be replaced or upgraded.

3. The location of public services is unbalanced. Quality public services are disproportionately located in city centers.

4. Lack of social trust in cities in the PRC.

5. Improvements to urban infrastructure, particularly in terms of drainage, water supply, and traffic, are needed.

6. Time: urbanization process in the PRC continues at high speed, creating challenges in terms of response.

7. The need for increased focus on the relationship between urban and rural development.

\section{Lao People's Democratic Republic}

1. Identification of environmental protection areas, and acting to protect them.

2. Concern with public parks, green areas, and open spaces suitable for people to use, with easy access.

3. Application of appropriate technologies to enhance land efficiency and effectiveness of waste treatment.

4. Pursuit of sustainable architecture.

5. Initiatives to address motorization and support the use of public transportation, including light-rail transit.

6. Policies to address car parking in cities.

\section{Myanmar}

1. The PRC's increasing concern for housing delivery, reflected in comprehensive national and local housing delivery planning, focusing on affordable housing.

2. Learning from the PRC's comprehensive system for urban planning, including regulations, standards, and codes.

3. The PRC's focus on key urban issues and addressing them in a step-by-step manner. 


\section{Thailand}

1. The PRC's efforts to incorporate the preferences of people in their urban planning.

2. The need for strong financial support from national and local governments to support heritage preservation.

3. The benefits of strong and fast-acting governance, e.g., rapid reconstruction after natural disasters.

4. Benefits of strong governance in terms of regulation enforcement.

5. The PRC's adoption of high technology in terms of architecture, construction, and transportation systems.

\section{Viet Nam}

1. Increased understanding of the PRC's urban and rural development at different stages, especially the main features of each stage, and how the PRC responded.

2. Increased understanding of the comprehensive urban and rural planning laws and regulations in the PRC.

3. Increased understanding of the importance of TOD, compact spatial planning, and density levels and distribution in pursuing climate change mitigation goals.

4. Learning from the PRC's heritage preservation planning, particularly methods deployed.

\section{Site Learning}

Parallel with the daily lectures and discussions, a series of field trips was conducted from midafternoon on Tuesday through Friday. These field visits provided participants with insight into city-building processes in an area of the PRC where urbanization is rapid, driven by cross-border dynamics (particularly the "South Silk Road" corridor which passes through Baoshan municipality where Tengchong is located), tourism and amenity development, and natural resource-based development. During the field trips, participants were given the opportunity to observe urban dynamics driven by tourism and amenity (second homes, amenity migration, etc.), a very significant driver of urbanization in the GMS countries, a commonality that helps define the GMS. 


\section{Proceedings of the Greater Mekong Subregion Urban Development and Planning Training Program}

Almost half of Asia's residents live in urban areas where the population is increasing by about 44 million each year. This report summarizes the 5 -day training program on the urban development and planning experience of the People's Republic of China (PRC). It was held 11-15 May 2015 in Yunnan Province, the PRC, for the benefit of key officials of the Greater Mekong Subregion countries-Cambodia, the PRC, the Lao People's Democratic Republic, Myanmar, Thailand, and Viet Nam. Discover the challenges arising from the speed and scale of the PRC's urban development in the areas of environmental degradation, inadequacy of social services, and inequality in standards of living. Find out how the PRC's urban development experience gave birth to valuable lessons which can be adopted by the Greater Mekong Subregion countries.

\section{About the Asian Development Bank}

ADB's vision is an Asia and Pacific region free of poverty. Its mission is to help its developing member countries reduce poverty and improve the quality of life of their people. Despite the region's many successes, it remains home to a large share of the world's poor. ADB is committed to reducing poverty through inclusive economic growth, environmentally sustainable growth, and regional integration.

Based in Manila, ADB is owned by 67 members, including 48 from the region. Its main instruments for helping its developing member countries are policy dialogue, loans, equity investments, guarantees, grants, and technical assistance.

\section{RKSI}

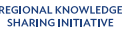

